"Period Prevalence and Perceived Side Effects of Hormonal Contraceptive Use and the Menstrual Cycle in Elite Athletes" by Martin D, Sale C, Cooper SB, Elliott-Sale KJ

International Journal of Sports Physiology and Performance

(C) 2017 Human Kinetics, Inc.

Note. This article will be published in a forthcoming issue of the International Journal of Sports Physiology and Performance. The article appears here in its accepted, peer-reviewed form, as it was provided by the submitting author. It has not been copyedited, proofread, or formatted by the publisher.

Section: Original Investigation

Article Title: Period Prevalence and Perceived Side Effects of Hormonal Contraceptive Use and the Menstrual Cycle in Elite Athletes

Authors: Daniel Martin ${ }^{\mathrm{a}, \mathrm{b}}$, Craig Sale ${ }^{\mathrm{a}}$, Simon B Cooper ${ }^{\mathrm{a}}$, and Kirsty J Elliott-Sale ${ }^{\mathrm{a}}$

Affiliations: ${ }^{a}$ Nottingham Trent University, School of Science and Technology, Nottingham,

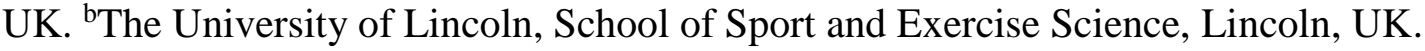

Journal: International Journal of Sports Physiology and Performance

Acceptance Date: December 18, 2017

(C2017 Human Kinetics, Inc.

DOI: https://doi.org/10.1123/ijspp.2017-0330 
"Period Prevalence and Perceived Side Effects of Hormonal Contraceptive Use and the Menstrual Cycle in Elite Athletes" by Martin D, Sale C, Cooper SB, Elliott-Sale KJ

International Journal of Sports Physiology and Performance

(C) 2017 Human Kinetics, Inc.

\section{Period prevalence and perceived side effects of hormonal contraceptive use and the menstrual cycle in elite athletes}

Submission type: Original Investigation

Daniel Martin $^{\mathrm{a}, \mathrm{b}}$, Craig Sale ${ }^{\mathrm{a}}$, Simon B Cooper ${ }^{\mathrm{a}}$, \& Kirsty J Elliott-Sale ${ }^{\mathrm{a}}$

${ }^{a}$ Nottingham Trent University, School of Science and Technology, Nottingham, UK
${ }^{b}$ The University of Lincoln, School of Sport and Exercise Science, Lincoln, UK

Corresponding Author:

Dr Kirsty Elliott-Sale, Head of Musculoskeletal Physiology Research Group, Sport Health and Performance Enhancement Research Centre, School of Science and Technology, Nottingham Trent University, Clifton Campus, Nottingham, UK, NG11 8NS; Telephone: +44 (0)115 848 6338; E-mail: kirsty.elliottsale@ntu.ac.uk

Running head: Hormonal contraceptive use in athletes

Abstract word count: 242

Text-only word count: 3368 
"Period Prevalence and Perceived Side Effects of Hormonal Contraceptive Use and the Menstrual Cycle in Elite Athletes" by Martin D, Sale C, Cooper SB, Elliott-Sale KJ

International Journal of Sports Physiology and Performance

(C) 2017 Human Kinetics, Inc.

\section{Abstract}

Purpose: To identify the period prevalence of hormonal contraceptive (HC) use and characterise the perceived side effects associated with the menstrual cycle and HC use. Methods: 430 elite female athletes completed a questionnaire to assess; the period prevalence of $\mathrm{HC}$ use, the reasons for initiation and discontinuation of $\mathrm{HCs}$ and the side effects experienced by $\mathrm{HC}$ and non-HC users. Descriptive statistics, between-group comparisons and associations between categorical variables were calculated. Results: $49.5 \%$ of athletes were currently using HCs and $69.8 \%$ had used HCs at some point. Combined oral contraceptives were most commonly used (68.1\%), with $30.0 \%$ using progestin-only contraceptives (implant $=13.1 \%$; injection $=3.7 \%$; intrauterine system $=2.8 \%$ ). Perceived negative side effects were more common with progestin-only $\mathrm{HC}$ use $(39.1 \%)$ compared to combined $\mathrm{HC}$ use $(17.8 \% ; \mathrm{P}=$ $0.001)$ and were most prevalent in implant users $(53.6 \% ; \mathrm{P}=0.004)$. HC users reported perceived positive side effects relating to the ability to predict and/or manipulate the timing, frequency and amount of menstrual bleeding. Non-HC users had a menstrual cycle length of $29 \pm 5 \mathrm{~d}$ and $77.4 \%$ reported negative side effects during their menstrual cycle, primarily during days 1-2 of menstruation (81.6\%). Conclusions: Approximately half of elite athletes used HCs and progestin-only contraceptive users reported greater incidences of negative side effects, especially with the implant. Due to the high inter-individual variability in reported side effects, athletes and practitioners should maintain an open dialogue to pursue the best interests of the athlete.

Keywords: menstrual cycle, hormonal contraceptives, side-effects, female athletes, prevalence 
"Period Prevalence and Perceived Side Effects of Hormonal Contraceptive Use and the Menstrual Cycle in Elite Athletes" by Martin D, Sale C, Cooper SB, Elliott-Sale KJ

International Journal of Sports Physiology and Performance

(C) 2017 Human Kinetics, Inc.

\section{Introduction}

Alterations to the female reproductive-axis influence health and athletic performance. ${ }^{1-}$

${ }^{3}$ Between menarche and the menopause, non-hormonal contraceptive users typically have a monthly menstrual cycle, with a cyclical rise and fall in sex hormone concentrations. ${ }^{4}$ Primary dysmenorrhea, which is characterised by painful menstruation, nausea, headaches, fatigue and diarrhoea, ${ }^{5}$ is experienced by $60-91 \%$ of non-hormonal contraceptive users ${ }^{6}$ and may affect athletic performance. ${ }^{7}$ In a recent study, $51 \%$ of athletes $(n=90)$ perceived that the menstrual cycle affected their training and performance. ${ }^{8}$ Despite this, little is known about menstrual cycle related side effects, when they occur and how training and performance may be influenced.

Hormonal contraceptives (HCs) are exogenous steroid hormones that inhibit ovulation and result in consistently low endogenous sex hormone concentrations, which can be used to treat dysmenorrhea., ${ }^{9,10}$ There are different delivery methods for HCs including the oral contraceptive (OC), implant, injection, transdermal patch, vaginal ring and intra-uterine system (IUS). In the UK, a hormone releasing coil is typically referred to as an IUS, whereas a copperbased, non-hormone releasing coil is referred to as an intra-uterine device (IUD) and, as such, would not be considered a type of HC. Hormonal contraceptives can also be classified by type; combined, with an oestrogenic and progestin component, or progestin-only. The type and concentration of oestrogen and progestin varies between different preparations of contraceptive, and may influence the physiological response. ${ }^{11-13}$

In a large-scale epidemiological study of $>194,000$ women, Cea-Soirano et al. ${ }^{14}$ reported that $30 \%$ of 16-49 year olds in the UK used HCs: combined OCs (16.2\%), progestinonly OCs (5.6\%), IUSs (4.2\%), injections (2.4\%), implants (1.5\%), transdermal contraceptive patches $(0.1 \%)$, with $4.5 \%$ using non-hormonal copper-based coils (IUDs). The prevalence of $\mathrm{HC}$ use in athletes has been poorly defined by previous research. In elite Norwegian athletes, 
"Period Prevalence and Perceived Side Effects of Hormonal Contraceptive Use and the Menstrual Cycle in Elite Athletes" by Martin D, Sale C, Cooper SB, Elliott-Sale KJ

International Journal of Sports Physiology and Performance

(c) 2017 Human Kinetics, Inc.

OC use was $40.2 \%$, which was significantly higher than a control population $(27 \%),{ }^{15}$ while $46 \%$ of Swedish football, volleyball and basketball athletes used OCs. ${ }^{16}$ Other studies have reported low OC use in athletes $(\sim 14 \%),{ }^{17,18}$ although this may be due to the inclusion of nonelite athletes, who may be more analogous to the general population. Previous research in elite athletes has only reported OC use and has not considered other delivery methods of HCs or detailed the preparations used by participants, which influence endogenous hormone concentrations and other physiological processes. ${ }^{11-13}$ No study has identified the reasons why elite athletes initiate or discontinue $\mathrm{HC}$ use, or the perceived side effects.

Elite female athletes are required to train and compete whilst having to manage changes in sex hormone concentration and their subsequent side effects. The current lack of understanding of these side effects is a barrier to implementing strategies to support athletes and promote optimal health and performance. The aim of this study was to identify (1) the period prevalence of $\mathrm{HC}$ use, (2) the reasons for initiation and discontinuation of HCs and (3) the side effects experienced by $\mathrm{HC}$ users and non-users in an elite athletic population.

\section{Materials and methods}

\section{Participants}

Between 2015-2016, elite female athletes were recruited through National Governing Bodies, coaching and support staff, or by approaching the athletes directly. Athletes had to be $>18 \mathrm{y}$ and competing at a national, international or professional (full-time and salaried) level. A paper-based questionnaire was used in order to minimise the possibility that the questionnaire could be completed by the non-targeted population. ${ }^{19}$ A total of 476 athletes completed the questionnaire, with 430 responses included in the final analysis (Figure 1). Athletes were recruited from 24 sports with 361 competing at an international/professional 
"Period Prevalence and Perceived Side Effects of Hormonal Contraceptive Use and the Menstrual Cycle in Elite Athletes" by Martin D, Sale C, Cooper SB, Elliott-Sale KJ

International Journal of Sports Physiology and Performance

(C) 2017 Human Kinetics, Inc.

level and 69 competing nationally. All participants provided written informed consent and the study was approved by the Nottingham Trent University non-invasive ethics committee.

\section{Questionnaire}

Data were collected using a paper-based questionnaire that was specifically designed for the purposes of the study. All data were provided by the athletes and reflect their perceptions and experiences. Participants recorded demographic information including age, height, weight, age of menarche, sport, competitive level, length of time competing at this level and weekly training frequency and duration (Table 1 and Figure 1). Current HC users and non-HC users were directed to complete different sections of the questionnaire. Non-HC users were asked whether they used a IUD, their typical menstrual cycle duration and variability in length. Participants were asked to state whether they experienced pain or other symptoms during the menstrual cycle and whether they avoided exercise/training at any point of their cycle. Where applicable, participants were asked, in an open-ended question, to state the symptoms/reasons and time points when these occurred. Current $\mathrm{HC}$-users were asked to provide the delivery method, preparation and duration of use for their current HC. Participants were asked whether they had discussed their $\mathrm{HC}$ with their coach/team doctor and whether the coach/team doctor was involved in the decision to use this type of HC. Participants were asked why they had chosen this method of $\mathrm{HC}$, whether they considered possible side effects prior to commencing $\mathrm{HC}$ use, and whether they have experienced any negative or positive side effects. Where applicable, participants were asked to provide supporting information in an open-ended question. Non-HC users and $\mathrm{HC}$ users were then asked to detail previous $\mathrm{HC}$ use, including the delivery method, preparation, duration of use and reason for discontinuation for all previous HCs used. 
"Period Prevalence and Perceived Side Effects of Hormonal Contraceptive Use and the Menstrual Cycle in Elite Athletes" by Martin D, Sale C, Cooper SB, Elliott-Sale KJ

International Journal of Sports Physiology and Performance

(C) 2017 Human Kinetics, Inc.

\section{Data analysis}

Data were analysed using Microsoft Excel and IBM SPSS (v. 23.0). To prevent duplicate data, the database was searched for non-unique date of births and identical values were visually checked to assess whether the respondents were different. Athletes were categorised by competitive level (national or international/professional) to conduct a stratified analysis. For open-ended questions, a content analysis was conducted independently by two researchers (DM, KES) to categorise responses, whereby a frequency analysis was performed, which was checked for consistency. Differences between the researchers were resolved by discussion until a consensus was reached. Direct verbatim quotes were used to inform interpretation in some instances. Assumptions of normality were checked using the ShapiroWilk test and between group differences were examined using independent samples t-tests, Mann-Whitney U tests and Kruskal Wallis H tests. Pearson's chi-squared analyses were used to examine the relationships between categorical variables, with Fishers exact tests used where $<80 \%$ of expected cell counts were $>5 .{ }^{20}$ Data are represented as mean $\pm 1 \mathrm{SD}$, frequencies and percentages and statistical significance was set at $\mathrm{p} \leq 0.05$.

\section{Results}

Three hundred $(69.8 \%)$ athletes reported using HCs at some point, with $49.5 \%$ of athletes currently using HCs and 50.5\% not currently using any form of HC (Fig 1). Hormonal contraceptive users had a lower age of menarche $(\mathrm{p}=0.010)$ and length of time competing at current level $(\mathrm{p}=0.048)$ compared to non-HC users (participant characteristics in Table 1). Competitive level did not influence the prevalence of $\mathrm{HC}$ use $(\mathrm{p}>0.05)$.

\section{Menstrual cycle (non -hormonal contraceptive users)}

Three athletes described themselves as amenorrheic, although the questionnaire did not specifically ask this question. Thirty-four athletes did not report their menstrual cycle length or 
"Period Prevalence and Perceived Side Effects of Hormonal Contraceptive Use and the Menstrual Cycle in Elite Athletes" by Martin D, Sale C, Cooper SB, Elliott-Sale KJ

International Journal of Sports Physiology and Performance

(C) 2017 Human Kinetics, Inc.

did not provide enough information to interpret a response. Mean cycle length for the remaining athletes was $29 \pm 5 \mathrm{~d}$. Eight athletes reported a mean menstrual cycle duration of greater than 35 days and three athletes reported a mean menstrual cycle duration of less than 21 days. Onehundred and four (48.6\%) athletes stated that their menstrual cycle was non-variable in length, while $110(51.4 \%)$ athletes reported their cycle length to be variable with a mean variation of $9 \pm 9$ d. Copper IUDs were used by 2 participants (0.9\%); with a mean menstrual cycle length of $28 \pm 4 \mathrm{~d}$. Menstrual cycle-related negative symptoms were reported by 168 athletes $(77.4 \%)$ and categorical frequencies are presented in Table 2. Symptoms were experienced in the week prior to menstruation (25.0\%), during days 1 and 2 of menstruation (81.6\%) and between day 3 and the end of menstruation (28.9\%). Nine athletes (4.1\%) reported that they had to refrain from exercise at certain points of their menstrual cycle. Reasons included pain $(n=4)$, sickness $(n=2)$, or other reasons $(n=3)$, such as "Literally struggle to get out of bed so training is out of the question" or "at the beginning of the menstrual cycle I avoid to do tough session [sic]". Four athletes reported that they didn't refrain from exercise, although they provided additional comments stating "No - but only because I can't", "but struggle with contact [rugby]”, "but I get back cramps 1 week before when running" and "I don't avoid it but I do sometimes have to delay things until cramps calm down". One athlete stated that "If anything I have to increase it [exercise]. Helps to pass quicker by maybe a day and helps the pain”.

\section{Hormonal contraceptive use}

Combined HCs comprised $68.5 \%$ of $\mathrm{HC}$ use, with $30.0 \%$ using progestin-only and $1.9 \%$ using an unspecified type of OC. There was no difference in length of current HC use between combined $(4.6 \pm 3.7 \mathrm{y})$ and progestin-only HC users $(3.9 \pm 4.4 \mathrm{y} ; \mathrm{p}=0.193)$, or between different delivery methods $(\mathrm{p}=0.649)$. Oral contraceptives were the most widely used $(78.4 \%)$, followed by the implant (13.1\%), injection (3.8\%), IUS (2.8\%) and vaginal ring (0.5\%), with 
"Period Prevalence and Perceived Side Effects of Hormonal Contraceptive Use and the Menstrual Cycle in Elite Athletes" by Martin D, Sale C, Cooper SB, Elliott-Sale KJ

International Journal of Sports Physiology and Performance

(C) 2017 Human Kinetics, Inc.

one participant using a combination of the implant and OC. All combined OCs were monophasic and contained ethinyl oestradiol (EO) as the oestrogenic component in varying doses: $20 \mu \mathrm{g}(\mathrm{n}=4,2.8 \%), 30 \mu \mathrm{g}(\mathrm{n}=116,80.0 \%), 35 \mu \mathrm{g}(\mathrm{n}=19,13.1 \%)$. Six participants $(\mathrm{n}$ $=4.1 \%$ ) used combined preparations but did not specify the oestrogenic dose. Twelve different progestins were used in various doses, with Levonorgestrel accounting for $51.4 \%$ of progestin use.

The most common reason athletes chose their specific type/delivery method was ease of use (18.8\%), and the most common side effects considered prior to HC use were weight gain (33\%) and mood changes/swings (12.7\%). The side effects experienced by HC-users are shown in Table 3. Negative side effects were significantly more common with progestin-only HCs $(39.1 \%)$ compared to combined HCs $(17.8 \% ; \mathrm{p}=0.001)$ and were significantly more common in the implant $(53.6 \%)$ compared to other delivery methods $(p=0.004$; Table 4$)$. Type and delivery method of $\mathrm{HC}$ did not affect the prevalence of reported positive effects $(\mathrm{p}>0.05)$. HC users were significantly more likely to report positive effects of HCs than negative effects $(\mathrm{p}<$ $0.05)$.

International/professional athletes were significantly more likely to discuss $\mathrm{HC}$ use with their coach/team doctor $(25 \%)$ compared to national level athletes $(0 \% ; \mathrm{p}<0.001)$. Competitive level did not influence coach/team doctor involvement in the decision to initiate HC use $(p=0.070)$, although this did occur for $7.6 \%$ of international/professional athletes and no national level athletes. The coach/team doctor was involved in the decision to use HCs for $14(6.6 \%)$ athletes, of which 12 used OCs and 2 used an implant. Ultra-low dose EO $(20 \mu \mathrm{g})$ OCs accounted for $25 \%$ of OC use in this group, in comparison to $2.7 \%$ of overall OC use, which was a significant effect $(\mathrm{p}=0.010)$. Where the coach/team doctor was involved in the decision, athletes stated that they were prescribed these HCs for contrasting reasons including; 
"Period Prevalence and Perceived Side Effects of Hormonal Contraceptive Use and the Menstrual Cycle in Elite Athletes" by Martin D, Sale C, Cooper SB, Elliott-Sale KJ

International Journal of Sports Physiology and Performance

(C) 2017 Human Kinetics, Inc.

'Higher level of oestrogen", "Apparently lowest oestrogen", "Low hormones" and "In attempt to reduce monthly fluctuations in my performance and fatigue".

In total, $87(40.1 \%)$ non-HC users had previously used some form of HC, with 64 (30.0\%) current $\mathrm{HC}$ users previously using a different HC. There were 218 incidences of previous HC use, as some athletes had used $2(n=49), 3(n=13), 4(n=4)$ and $5(n=1)$ previous types of HC. Combined OCs accounted for $78.4 \%$ of previous use, with progestinonly OCs (7.8\%), implant (7.8\%), injection $(6.0 \%)$ and IUS (1.8\%) also used. The reasons provided for discontinuation of previous HCs are presented in Table 5. Mean duration of previous HC use was $2.2 \pm 2.3 \mathrm{y}$, with no difference between types $(\mathrm{p}=0.360)$ or delivery methods $(p=0.733)$.

\section{Discussion}

This novel study has shown that there is an approximately even prevalence of HC use and non-HC use in elite female athletes. The majority of female athletes have used HCs at some point in their sporting career. These results highlight the importance of understanding the effects of the menstrual cycle and HC use in elite sportswomen. This is the first study to detail the symptoms experienced by athletes during the menstrual cycle and with $\mathrm{HC}$ use, and these data can be used to inform the decisions of athletes, practitioners and researchers.

The prevalence of HC use in elite athletes $(49.5 \%)$ is higher than recent data for the general population of reproductive age in the UK $(30.0 \%)^{14}$ and USA $(27.6 \%) .{ }^{21}$ Sixty-nine percent of HCs used were combined OCs, which is also higher than in the general population where OCs account for $54.0 \%$ of HC use. ${ }^{14}$ Schaumberg et al. ${ }^{22}$, showed that competitive (state, national and international) athletes rated sport competition and sport training as more important factors in menstrual manipulation with OCs, compared to sub-elite and recreationally active individuals. Furthermore, $43.5 \%$ of OC-using competitive athletes planned to manipulate 
"Period Prevalence and Perceived Side Effects of Hormonal Contraceptive Use and the Menstrual Cycle in Elite Athletes" by Martin D, Sale C, Cooper SB, Elliott-Sale KJ

International Journal of Sports Physiology and Performance

(C) 2017 Human Kinetics, Inc.

menstruation often, which was greater than sub-elite (22.5\%) and recreationally active women $(15.8 \%)$. In the current study, nearly a third of combined OC users perceived the ability to predict or manipulate menstruation, thereby avoiding menstruation during training or competition, as a positive effect, which may explain the differences in OC use between elite athletes and the general population. Progestin-only HCs accounted for $30.0 \%$ of use, with the implant (13.1\%) and progestin-only OC (10.3\%) being the most widely used. Almost $40 \%$ of progestin-only $\mathrm{HC}$ users perceived the cessation of, or less frequent bleeding, as a positive consequence of this type of HC. Previous research has documented the prevalence of OC use in athletes. ${ }^{15,16}$ however the current study has provided a more comprehensive overview of HC use by including all types and delivery methods of $\mathrm{HCs}$, in addition to the preparations, which enables the quantification of steroid hormone content and concentrations. Twelve different progestins were used in varying concentrations, with EO being the oestrogenic component in all combined preparations. Four HC users were prescribed ultra-low dose (20 $\mu \mathrm{g}$ EO) OCs; with three cases involving the coach/team doctor in the decision to use this preparation, all of which were from different sports. Ultra-low dose OCs are associated with reduced headaches, nausea and breast tenderness compared to higher dose EO formulations ${ }^{23}$ and can reduce the symptoms of dysmenorrhea ${ }^{24}$, so may have been prescribed to reduce these symptoms whilst maintaining the benefits of improved cycle control. These data are representative of a UK based population and further studies are required to expand this knowledge to other countries where the use of other formulations, such as extended cycle OCs, are more prevalent. ${ }^{25}$

Combined HCs were better tolerated than progestin-only $\mathrm{HCs}$; with $17.8 \%$ of combined-type users reporting negative side effects in comparison to $39.1 \%$ of progestin-only HC users. In particular, the implant had a significantly higher incidence of reported negative symptoms compared to other delivery methods of HCs (Table 4). One third of athletes considered weight gain as potential side effect prior to $\mathrm{HC}$ initiation, although only $7.5 \%$ 
"Period Prevalence and Perceived Side Effects of Hormonal Contraceptive Use and the Menstrual Cycle in Elite Athletes" by Martin D, Sale C, Cooper SB, Elliott-Sale KJ

International Journal of Sports Physiology and Performance

(C) 2017 Human Kinetics, Inc.

reported increased weight which is lower than in the general population (34\%). ${ }^{26}$ Hormonal contraceptive users were more likely to report positive than negative side effects, which may have implications for athletes considering $\mathrm{HC}$ use in the future. Nineteen negative and 23 positive categories of side effects were identified, emphasising the individuality of responses and that athletes should be considered on a case by case basis. The most prevalent, positive side effects reported were the ability to predict/change menstruation $(n=45)$, having regular periods $(n=27)$ and cessation of/less frequent bleeding $(n=26)$, showing that changes to the timing, frequency and amount of bleeding with $\mathrm{HC}$ use were well-received. It should be noted that athletes were asked to state the non-contraceptive benefits of $\mathrm{HC}$ use, therefore the primary benefit and reason of HC use may have been for contraception.

Sixty-four (30.0\%) HC users previously used a different form of HC and 87 (40.1\%) non-HC users had previously used a form of HC. The most common reasons provided for discontinuation of HCs were: they were no longer needed (19.9\%), they altered $\operatorname{mood}(19.2 \%)$, resulted in weight gain (18.5\%) and caused headaches/migraines (11.9\%). It is important to note that 46 separate reasons were provided for discontinuation of HCs, emphasising the high inter-individual response. This further emphasises that sport practitioners should openly discuss HC use and side effects with athletes to monitor athletes' health, well-being and performance.

Negative side effects associated with the menstrual cycle were reported by $77.4 \%$ of non-HC users, which is similar to the general population. ${ }^{6}$ Exercise may reduce the occurrence and severity of dysmenorrhea, ${ }^{27}$ although dysmenorrhea is still widespread in elite athletes. The most commonly reported side effects were stomach cramps (47.5\%), unspecified cramps (22.1\%), back pain $(17.1 \%)$ and headaches/migraines $(9.7 \%)$. Despite having physically demanding lifestyles, only $4.2 \%$ of athletes stated that they refrained from exercise at certain points of their menstrual cycle, which is lower than the general population where dysmenorrhea 
"Period Prevalence and Perceived Side Effects of Hormonal Contraceptive Use and the Menstrual Cycle in Elite Athletes" by Martin D, Sale C, Cooper SB, Elliott-Sale KJ

International Journal of Sports Physiology and Performance

(C) 2017 Human Kinetics, Inc.

limits daily activities in $15-29 \%$ of women. ${ }^{6}$ This discrepancy may be caused by internal and external pressures to perform, ${ }^{28}$ meaning that athletes persevere with training whilst experiencing severe symptoms, evidenced by responses such as “No, but only because I can't [avoid exercise]". A recent study in HC users and non-users, showed 51.1\% of athletes thought their menstrual cycle affected training and performance, ${ }^{8}$ although the current data indicates that this rarely translates into athletes modifying training schedules to accommodate symptoms.

Twenty-four distinct, negative symptoms were reported by non-HC users (Table 2) and approximately half of the athletes reported menstrual cycle length variability with a relatively high mean variation of $(9 \pm 9 d)$ in these athletes. Although the current questionnaire did not ask specifically about amenorrhea, three athletes described themselves as amenorrheic, and we recommend that future studies explicitly ask this question in order to not under-represent the occurrence of amenorrhea in elite sport. Side effects were mostly experienced during the first two days of menstruation (81.6\%), however also occurred in the week prior to menstruation (25.0\%) and between day 3 and the end of menstruation (28.9\%). These data emphasise the individuality of responses and the importance of athletes monitoring their menstrual cycle and associated symptoms. We suggest that athletes and coaches/support staff should maintain an open dialogue about the menstrual cycle and encourage flexibility in training schedules, when possible, to accommodate the most severe side effects.

With half of elite athletes using $\mathrm{HCs}$, future research should include $\mathrm{HC}$ users and nonusers in order to represent the female athlete population. Progestin-only contraceptives constitute $\sim 30 \%$ of $\mathrm{HC}$ use in athletes, although we are unaware of any research available to identify the effects of these contraceptives on athletic performance and health. Twenty-five different preparations of $\mathrm{HC}$ were identified in this study, containing different doses of oestrogens and progestins, which may have different physiological effects. ${ }^{11-13}$ Therefore, future research should focus on (1) examining differences in responses between $\mathrm{HC}$ users and 
"Period Prevalence and Perceived Side Effects of Hormonal Contraceptive Use and the Menstrual Cycle in Elite Athletes" by Martin D, Sale C, Cooper SB, Elliott-Sale KJ

International Journal of Sports Physiology and Performance

(C) 2017 Human Kinetics, Inc.

non-users, (2) progestin-only contraceptive users and (3) differences between preparations of HC.

\section{Practical Applications}

Progestin-only contraceptives had a greater incidence of negative side effects and physicians may want to consider the increased prevalence of perceived negative side effects with these contraceptives. There is a large degree of individuality in the type and severity of symptoms experienced during the menstrual cycle and $\mathrm{HC}$ use, and in the reasons for initiating and discontinuing $\mathrm{HC}$ use. It is recommended that athletes and practitioners discuss side effects experienced with the menstrual cycle and $\mathrm{HC}$ use in order to suit the athletes' best interests. This research also highlights that future research should include HC users and non-users in order to represent the female athlete population.

\section{Conclusions}

Approximately half of elite athletes use some type of $\mathrm{HC}$, with combined OCs most commonly used, possibly due to the ability to predict and/or manipulate the timing, frequency and amount of menstrual bleeding. A large proportion of sportswomen use progestin-only contraceptives with a perceived benefit being that they induce amenorrhea. There is a larger inter-individual variability in response to $\mathrm{HC}$ use and the menstrual cycle which should be considered by athletes and practitioners.

\section{Acknowledgements:}

None.

\section{Conflicts of interest:}

None. 
"Period Prevalence and Perceived Side Effects of Hormonal Contraceptive Use and the Menstrual Cycle in Elite Athletes" by Martin D, Sale C, Cooper SB, Elliott-Sale KJ

International Journal of Sports Physiology and Performance

(C) 2017 Human Kinetics, Inc.

\section{References}

1. Cable NT, Elliott KJ. The influence of reproductive hormones on muscle strength. Biol Rhythm Res. 2004;35:235-244.

2. De Souza MJ, Nattiv A, Joy E, et al. 2014 Female Athlete Triad Coalition Consensus Statement on Treatment and Return to Play of the Female Athlete Triad: 1st International Conference held in San Francisco, California, May 2012 and 2nd International Conference held in Indianapolis, Indiana, M. Br J Sports Med. 2014;48:289.

3. Mountjoy M, Sundgot-Borgen J, Burke L, et al. The IOC consensus statement: beyond the Female Athlete Triad--Relative Energy Deficiency in Sport (RED-S). Br J Sports Med. 2014;48:491-497.

4. Stricker R, Eberhart R, Chevailler MC, et al. Establishment of detailed reference values for luteinizing hormone, follicle stimulating hormone, estradiol, and progesterone during different phases of the menstrual cycle on the Abbott ARCHITECT analyzer. Clin Chem Lab Med. 2006;44:883-887.

5. Brown J, Brown S. Exercise for dysmenorrhoea. Cochrane Datab Syst Rev. 2010:CD004142.

6. Ju H, Jones M, Mishra G. The prevalence and risk factors of dysmenorrhea. Epidemiol Rev. 2014;36:104-113.

7. Chantler I, Mitchell D, Fuller A. Diclofenac potassium attenuates dysmenorrhea and restores exercise performance in women with primary dysmenorrhea. J Pain. 2009;10:191-200.

8. Bruinvels G, Burden R, Brown N, Richards T, Pedlar C. The prevalence and impact of heavy menstrual bleeding (menorrhagia) in elite and non-elite athletes. PLoS One. 2016;11:e0149881.

9. Wong CL, Farquhar C, Roberts H, Proctor M. Oral contraceptive pill as treatment for primary dysmenorrhoea. Cochrane Datab Syst Rev. 2009:CD002120.

10. Imai A, Matsunami K, Takagi H, Ichigo S. Levonorgestrel-releasing intrauterine device used for dysmenorrhea: five-year literature review. Clin Exp Obstet Gynecol. 2014;41:495-498.

11. Elliott-Sale KJ, Smith S, Bacon J, et al. Examining the role of oral contraceptive users as an experimental and/or control group in athletic performance studies. Contraception. 2013;88:408-412.

12. Godsland IF, Crook D, Simpson R, et al. The effects of different formulations of oral contraceptive agents on lipid and carbohydrate metabolism. $N$ Engl J Med. 1990;323:1375-1381.

13. Van Den Heuvel MW, Van Bragt AJM, Alnabawy AKM, Kaptein MCJ. Comparison of ethinylestradiol pharmacokinetics in three hormonal contraceptive formulations: The vaginal ring, the transdermal patch and an oral contraceptive. Contraception. 2005;72:168-174. 
"Period Prevalence and Perceived Side Effects of Hormonal Contraceptive Use and the Menstrual Cycle in Elite Athletes" by Martin D, Sale C, Cooper SB, Elliott-Sale KJ

International Journal of Sports Physiology and Performance

(c) 2017 Human Kinetics, Inc.

14. Cea-Soriano L, García Rodríguez LA, Machlitt A, Wallander MA. Use of prescription contraceptive methods in the UK general population: a primary care study. BJOG An Int J Obstet Gynaecol. 2014;121:53-61.

15. Torstveit MK, Sundgot-Borgen J. Participation in leanness sports but not training volume is associated with menstrual dysfunction: a national survey of 1276 elite athletes and controls. Br J Sports Med. 2005;39:141-147.

16. Brynhildsen J, Lennartsson H, Klemetz, et al. Oral contraceptive use among female elite athletes and age-matched controls and its relation to low back pain. Acta Obstet Gynecol Scand. 1997;76:873-878.

17. Thein-Nissenbaum JM, Carr KE, Hetzel, Dennison E. Disordered eating, menstrual irregularity, and musculoskeletal injury in high school athletes. Sports Health. 2014;6:313-320.

18. Thyssen HH, Clevin L, Olesen S, Dennison E. Urinary incontinence in elite female athletes and dancers. Int Urogynecol J Pelvic Floor Dysfunct. 2002;13:15-17.

19. Wright KB. Researching Internet-Based Populations: Advantages and disadvantages of online survey research, online questionnaire authoring software packages, and web survey services. J Comput Commun. 2006;10:00-00.

20. Quinn GP, Keogh MJ. Experimental Design and Data Analysis for Biologists. New York: Cambridge University Press; 2002

21. Daniels K, Daugherty J, Jones J. Current contraceptive status among women aged 1544: United States, 2011-2013. NCHS Data Brief. 2014:1-8.

22. Schaumberg MA, Emmerton LM, Jenkins DG, et al. Oral contraceptive use for manipluation of menstruation in young, physically active women. Int $J$ Sports Physiol Perform. 2017; May 1:1-20 [Epub ahead of print].

23. Vitzthum VJ, Ringheim K. Hormonal contraception and physiology: a research-based theory of discontinuation due to side effects. Stud Fam Plann. 2005;36:13-32.

24. Harada T, Momoeda M. Evaluation of an ultra-low-dose oral contraceptive for dysmenorrhea: a placebo-controlled, double-blind, randomized trial. Fertil Steril. 2016;106:1807-1814.

25. Hall KS, Trussell J. Types of combined oral contraceptives used by U.S. women. Contraception. 2012;86:659-665.

26. Nault AM, Peipert JF, Zhao Q, Madden T, Secura GM. Validity of perceived weight gain in women using long-acting reversible contraception and depot medroxyprogesterone acetate. Am J Obstet Gynecol. 2013;208:48.e1-8.

27. Daley AJ. Exercise and primary dysmenorrhoea : a comprehensive and critical review of the literature. Sports Med. 2008;38:659-670.

28. McKay J, Niven AG, Lavallee D, White A. Sources of strain among elite UK track athletes. Sport Psychol. 2008;22:143-163. 


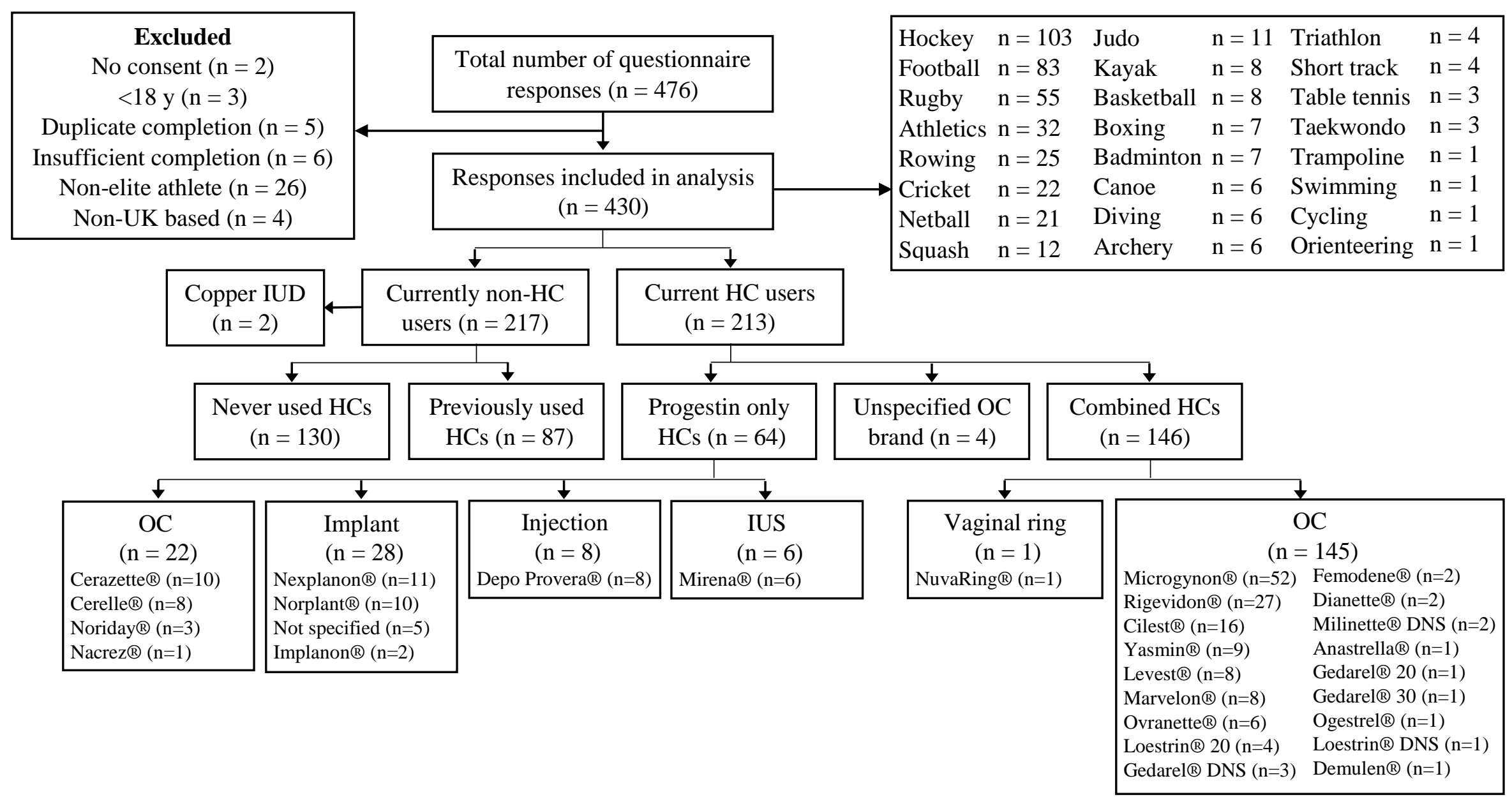

Figure 1. The prevalence of type, delivery method and preparation of hormonal contraceptives (HCs) used and the prevalence of non-HC use. IUD, Intrauterine device; IUS, Intrauterine system; DNS, dose not specified; OC, oral contraceptive. 
"Period Prevalence and Perceived Side Effects of Hormonal Contraceptive Use and the Menstrual Cycle in Elite Athletes" by Martin D, Sale C, Cooper SB, Elliott-Sale KJ

International Journal of Sports Physiology and Performance

(c) 2017 Human Kinetics, Inc.

Table 1. Participant characteristics for hormonal contraceptive (HC) users and non-HC users.

\begin{tabular}{lccc} 
Demographic information & HC users & Non HC users & Total \\
\hline Age $(\mathrm{y})$ & $24.1 \pm 4.5$ & $24.3 \pm 4.3$ & $24.2 \pm 4.4$ \\
Height $(\mathrm{m})$ & $1.7 \pm 0.1$ & $1.7 \pm 0.1$ & $1.7 \pm 0.1$ \\
Weight $(\mathrm{kg})$ & $66.2 \pm 9.8$ & $66.0 \pm 9.3$ & $66.1 \pm 9.6$ \\
Body mass index $\left(\mathrm{kg} \cdot \mathrm{m}^{2}\right)$ & $23.1 \pm 2.6$ & $23.0 \pm 2.5$ & $23.1 \pm 2.5$ \\
Age at menarche $(\mathrm{y})$ & $13.4 \pm 1.5$ & $13.8 \pm 1.3$ & $13.6 \pm 1.4^{*}$ \\
Gynaecological age (y) & $10.7 \pm 4.6$ & $10.6 \pm 4.6$ & $10.6 \pm 4.6$ \\
Duration competing at current level (y) & $5.0 \pm 3.6$ & $5.7 \pm 4.1$ & $5.4 \pm 3.9^{*}$ \\
No. training session per week & $8.5 \pm 4.5$ & $8.4 \pm 4.0$ & $8.5 \pm 4.3$ \\
Average training session duration (mins) & $92.8 \pm 29.8$ & $89.1 \pm 27.8$ & $90.9 \pm 28.8$ \\
Total weekly training duration (mins) & $769.7 \pm 440.8$ & $720.3 \pm 385.6$ & $744.6 \pm 413.9$ \\
\hline
\end{tabular}

* Indicates a significant difference between HC users and non-HC users $(\mathrm{p}<0.05)$ 
"Period Prevalence and Perceived Side Effects of Hormonal Contraceptive Use and the Menstrual Cycle in Elite Athletes" by Martin D, Sale C, Cooper SB, Elliott-Sale KJ

International Journal of Sports Physiology and Performance

(c) 2017 Human Kinetics, Inc.

Table 2. Frequency and prevalence of physical and emotional symptoms reported during the menstrual cycle for non-hormonal contraceptive users.

\begin{tabular}{llcc} 
& Symptom & Frequency & Prevalence (\%) \\
\hline Physical & Stomach cramps/abdominal pain & 103 & 47.5 \\
& Unspecified cramp & 48 & 22.1 \\
Back pain & 37 & 17.1 \\
Headache/migraine & 21 & 9.7 \\
Bloating & 12 & 5.5 \\
Nausea/sickness/vomiting & 10 & 4.6 \\
Tiredness/fatigue/lethargy & 9 & 4.1 \\
Dizzy/lightheaded/lack of coordination & 5 & 2.3 \\
Leg discomfort & 4 & 1.8 \\
Unspecified pain & 3 & 1.4 \\
Hot flushes/sweating & 2 & 0.9 \\
Hunger/increased appetite & 2 & 0.9 \\
Sore breasts & 2 & 0.9 \\
Bad skin & 1 & 0.5 \\
Constipation & 1 & 0.5 \\
Heavy bleeding & 1 & 0.5 \\
Muscle ache & 1 & 0.5 \\
Problems with exercise & 1 & 0.5 \\
Sore throat & 1 & 0.5 \\
Tight neck & 1 & 0.5 \\
Weakness & 1 & 0.5 \\
\hline Mood changes/swings & 9 & 4.1 \\
Irritability & 1 & 0.5 \\
Flustered & 0.5 \\
\hline
\end{tabular}


"Period Prevalence and Perceived Side Effects of Hormonal Contraceptive Use and the Menstrual Cycle in Elite Athletes" by Martin D, Sale C, Cooper SB, Elliott-Sale KJ International Journal of Sports Physiology and Performance

(c) 2017 Human Kinetics, Inc.

Table 3. Prevalence of reported negative and positive side effects for current hormonal contraceptive use.

\begin{tabular}{|c|c|c|c|c|c|c|}
\hline & Negative effect & Frequency & Prevalence (\%) & Positive effect & Frequency & Prevalence $(\%)$ \\
\hline \multirow[t]{19}{*}{ Physical } & Weight gain & 16 & 7.5 & Regular period & 27 & 12.7 \\
\hline & Irregular periods & 9 & 4.2 & Cessation of/less frequent periods & 26 & 12.2 \\
\hline & Poor skin & 6 & 2.8 & Reduced bleeding/lighter periods & 23 & 10.8 \\
\hline & Headaches/migraines & 4 & 1.9 & Improved skin & 13 & 6.1 \\
\hline & Altered cycle length & 3 & 1.4 & Reduced period pain & 10 & 4.7 \\
\hline & Breast issues (bigger/sore) & 3 & 1.4 & Reduced cramps (unspecified) & 7 & 3.3 \\
\hline & Constant/irregular bleeding & 3 & 1.4 & Reduced pain (unspecified) & 6 & 2.8 \\
\hline & Spotting & 3 & 1.4 & Reduced headaches/migraine & 3 & 1.4 \\
\hline & Tiredness/fatigue/lethargy & 3 & 1.4 & Increased iron & 3 & 1.4 \\
\hline & Effect on training/performance & 2 & 0.9 & Less ill/sick & 3 & 1.4 \\
\hline & Nausea/sickness/vomiting & 2 & 0.9 & Resumption of cycle from amenorrhea & 3 & 1.4 \\
\hline & Water retention & 2 & 0.9 & Reduced stomach cramps & 3 & 1.4 \\
\hline & Abnormal liver function & 1 & 0.5 & Effect on training/performance & 2 & 0.9 \\
\hline & Bloating & 1 & 0.5 & Reduced bloating & 1 & 0.5 \\
\hline & Hormone imbalance & 1 & 0.5 & Improved bone density & 1 & 0.5 \\
\hline & Increased appetite & 1 & 0.5 & Less faint & 1 & 0.5 \\
\hline & Stomach pain & 1 & 0.5 & Reduced fluctuations in water retention & 1 & 0.5 \\
\hline & Unspecified pain & 1 & 0.5 & Reduced fluctuations in weight & 1 & 0.5 \\
\hline & & & & Reduced PCOS side effects & 1 & 0.5 \\
\hline Emotional & Mood changes/swings & 9 & 4.2 & Improved mood & 3 & 1.4 \\
\hline Both & & & & Helps PMT & 1 & 0.5 \\
\hline \multirow[t]{2}{*}{ Practical } & & & & Ability to predict/change cycle date & 45 & 21.1 \\
\hline & & & & Couldn't forget to take & 3 & 1.4 \\
\hline
\end{tabular}

PCOS, Polycystic ovarian syndrome; PMT, Pre-menstrual tension. 
"Period Prevalence and Perceived Side Effects of Hormonal Contraceptive Use and the Menstrual Cycle in Elite Athletes" by Martin D, Sale C, Cooper SB, Elliott-Sale KJ International Journal of Sports Physiology and Performance

(C) 2017 Human Kinetics, Inc.

Table 4. Prevalence of reported negative and positive effects of hormonal contraceptive use in current users, separated by type and delivery method of hormonal contraceptive

\begin{tabular}{|c|c|c|c|c|c|c|c|c|c|}
\hline & \multicolumn{3}{|c|}{ Type of hormonal contraceptive } & \multicolumn{6}{|c|}{ Delivery method of hormonal contraceptive } \\
\hline & Combined & $\begin{array}{c}\text { Progestin } \\
\text {-only } \\
\end{array}$ & Total & OC & Implant & Injection & IUS & $\begin{array}{c}\text { Vaginal } \\
\text { ring }\end{array}$ & Tota \\
\hline Experienced negative symptoms & 26 & 25 & 51 & 35 & 15 & 2 & 2 & 0 & 54 \\
\hline Didn't experience negative symptoms & 120 & 39 & 159 & 136 & 13 & 6 & 4 & 1 & 214 \\
\hline Percentage with symptoms (\%) & 17.8 & 39.1 & $24.4^{*}$ & 20.5 & 53.6 & 25.0 & 33.3 & 0.0 & $25.2^{*}$ \\
\hline Experienced positive effects & 99 & 42 & 141 & 117 & 18 & 3 & 5 & 1 & 144 \\
\hline Didn't experience positive effects & 47 & 22 & 69 & 54 & 10 & 5 & 1 & 0 & 70 \\
\hline Percentage with symptoms (\%) & 67.8 & 65.3 & 67.1 & 68.4 & 64.3 & 37.5 & 83.3 & 100.0 & 67.3 \\
\hline
\end{tabular}

* Indicates a significant effect of type or delivery method $(\mathrm{P}<0.05)$. OC, oral contraceptive; IUS, intrauterine system. 
"Period Prevalence and Perceived Side Effects of Hormonal Contraceptive Use and the Menstrual Cycle in Elite Athletes" by Martin D, Sale C, Cooper SB, Elliott-Sale KJ

International Journal of Sports Physiology and Performance

(C) 2017 Human Kinetics, Inc.

Table 5. Reasons, frequency and prevalence for discontinuation of previous hormonal contraceptives.

\begin{tabular}{|c|c|c|c|}
\hline & Reason & Frequency & Prevalence $(\%)$ \\
\hline \multirow[t]{30}{*}{ Physical symptoms } & Weight gain & 28 & 12.8 \\
\hline & Headaches/migraine & 18 & 8.3 \\
\hline & More frequent or heavier bleeding & 13 & 6.0 \\
\hline & Irregular/no bleeding & 10 & 4.6 \\
\hline & Poor skin & 7 & 3.2 \\
\hline & Constant bleeding & 6 & 2.8 \\
\hline & Fatigue/tiredness/lethargy & 6 & 2.8 \\
\hline & Bone health & 5 & 2.3 \\
\hline & Impaired training/performance/recovery & 5 & 2.3 \\
\hline & Nausea/vomiting & 4 & 1.8 \\
\hline & Resumption/regulation of menses & 4 & 1.8 \\
\hline & Stomach cramps & 3 & 1.4 \\
\hline & Stroke and cancer risk & 3 & 1.4 \\
\hline & Water retention & 3 & 1.4 \\
\hline & Cramps & 2 & 0.9 \\
\hline & Hormone imbalance & 2 & 0.9 \\
\hline & Impaired sleep & 2 & 0.9 \\
\hline & Low libido & 2 & 0.9 \\
\hline & Painful periods & 2 & 0.9 \\
\hline & Bloating & 1 & 0.5 \\
\hline & Blood pressure & 1 & 0.5 \\
\hline & Blood side effects [sic] & 1 & 0.5 \\
\hline & Breast pain & 1 & 0.5 \\
\hline & Dizziness and blurred vision & 1 & 0.5 \\
\hline & For oestrogen reasons [sic] & 1 & 0.5 \\
\hline & Hot flushes & 1 & 0.5 \\
\hline & Illness & 1 & 0.5 \\
\hline & Pain during intercourse & 1 & 0.5 \\
\hline & PMS & 1 & 0.5 \\
\hline & Removed to assess oestrogen level & 1 & 0.5 \\
\hline \multirow[t]{4}{*}{ Emotional symptoms } & Mood & 29 & 13.3 \\
\hline & Wanting to be "normal" / "natural" & 5 & 2.3 \\
\hline & Depression & 4 & 1.8 \\
\hline & Needed a rest/break & 3 & 1.4 \\
\hline \multirow[t]{12}{*}{ Practical } & Not sexually active/not needed & 30 & 13.8 \\
\hline & Forgetting to take pill & 16 & 7.3 \\
\hline & Doctor/nurse recommendation & 11 & 5.0 \\
\hline & Didn't like it & 10 & 4.6 \\
\hline & Pregnancy & 6 & 2.8 \\
\hline & New preparation/type & 4 & 1.8 \\
\hline & Ran out & 4 & 1.8 \\
\hline & Went abroad/travelling & 4 & 1.8 \\
\hline & Ineffective & 3 & 1.4 \\
\hline & Wanted something different/permanent & 2 & 0.9 \\
\hline & Word of mouth & 2 & 0.9 \\
\hline & Loss of effect[sic] & 1 & 0.5 \\
\hline
\end{tabular}

